\title{
The research on the change of the development index in high concentration polymer after polymer flooding
}

\author{
Di Wang ${ }^{1, ~ a ~, ~ Y u j i a ~ J i a o ~}{ }^{2, b}$ \\ ${ }^{1}$ School of Petrochemical Engineering, Northeast Petroleum University, Daqing 166318, China; \\ ${ }^{2}$ School of Petrochemical Engineering, Northeast Petroleum University, Daqing 166318, China; \\ a286788704@qq.com, b125812800@qq.com
}

Keywords: Reconstruction of well pattern,Coefficient of drag,Conformance efficiency

\begin{abstract}
In order to study the change principle of development biddingafter polymer flooding, the coefficient of drag and residual resistance factorare measured by flow test, and the reasonable injection rate is obtained by the injectability evaluation experiment.Oil displacement experiment is carried out in different types of wellsin large scale simulation physical model of high molecular weight polymer with relative molecular weight of 25000000 , the results show that the reconstruction of well pattern can greatly reduce the residual oil saturation and ease the pressure of injection continued rise; with the increase of polymer concentration, the conformance efficiency of middle and low permeability layerare improved; after the reconstruction of well pattern, the remaining oil located near the diversion line and the original oil well get utilized,displacement characteristicshas improved significantly.
\end{abstract}

\section{Introduction}

Polymer flooding is applied in various blocks of Daqing oil field to enhance recovery ratio ${ }^{[1]}$. The yield-increasing effect is significant and it brings good economic benefit for oil field ${ }^{[2]}$. However, in the production process at site, the polymer recovery increasing ratio reaches only $10 \%$ and there are still 50\% crude oils existed in reservoir. Therefore, it urgently needs to take new measures to dig the potential remaining oil after polymer flooding ${ }^{[3]} .2 .5 \times 107$ supra polymer high concentration polymer flooding technology is a technology to improve recovery ratio with good application effect after using polymer flooding ${ }^{[4]}$. Supra polymer high concentration polymer flooding has the problem of injection difficulty and excessive injection pressure . The above problems need to be solved urgently. The author studies the remaining oil distribution characteristic and the sweep coefficient variation of applying high concentration viscoelasticity polymer flooding on three-dimensional physical model after polymer flooding by using microelectrode and large-scale three-dimensional heterogeneous physical model, carries out interior displacement experiment of different displacement schemes and analyzes the effect of enhancing recovery ratio with different schemes.

Measure of resistance coefficient and residual resistance factor.For flow experiment measure, firstly inject polymer. When subsequent water content of water flooding reaches $92 \%$, measure resistance coefficient and residual resistance factor of oil layer for different concentration 25 million supra polymer solution. Measured experiment result of resistance coefficient and residual resistance factor is shown in Table 1. The variation comparison of the injection pressure difference of different concentrations of polymer is shown in Fig. 1. 


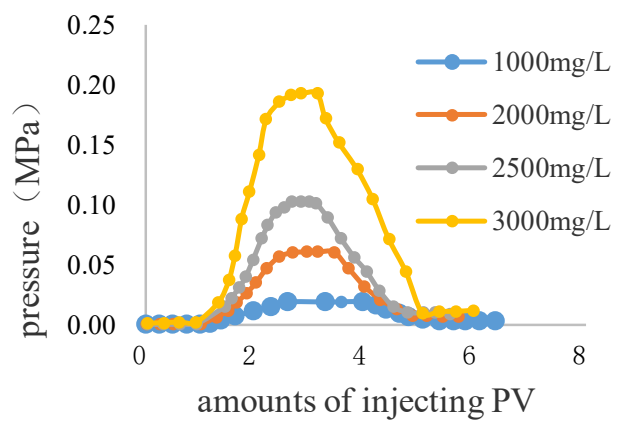

Fig. 1 the variation comparison of the injection pressure difference of different concentrations of polymer

Measured experimental result of residual resistance factor and resistance coefficient indicates that residual resistance factor caused by low concentration polymer $(1000 \mathrm{mg} / \mathrm{L})$ is low. When the concentration reaches $2000 \mathrm{mg} / \mathrm{L}$, the residual resistance factor increases with the increasing of concentration. When concentration exceeds $2500 \mathrm{mg} / \mathrm{L}$, the increasing of residual resistance factor becomes slow with the increasing of concentration. Even if residual resistance factor is high, the pressure is stable during injection process and there is no irreversible physical blocking occurred. In consideration of excessive residual resistance factor may cause excessive injection pressure during polymer injection process, thus, it suggests selecting polymer parameters with the residual resistance factor of 10 20 and determines polymer injection parameter further through polymer injectivity evaluation experiment.

Table 1 experimental results of resistance coefficient and residual resistance coefficient

\begin{tabular}{|c|c|c|c|c|c|c|}
\hline \multicolumn{3}{|c|}{ type and nature of polymer } & \multirow{2}{*}{$\begin{array}{c}\text { effective } \\
\text { permeability } \\
\text { of } \\
\text { core } / 10^{-3} \mu \mathrm{m} 2\end{array}$} & \multirow{2}{*}{$\begin{array}{c}\text { permeability of } \\
\text { core water after } \\
\text { polymer injection } \\
\qquad / 10^{-3} \mu \mathrm{m} 2\end{array}$} & \multirow{2}{*}{$\begin{array}{l}\text { residual } \\
\text { resistance } \\
\text { factor }\end{array}$} & \multirow{2}{*}{$\begin{array}{l}\text { resistanc } \\
\text { e } \\
\text { coefficie } \\
\text { nt }\end{array}$} \\
\hline $\begin{array}{l}\text { molecula } \\
\text { r weight }\end{array}$ & $\begin{array}{l}\text { concentrati } \\
\text { on } \\
\qquad / \mathrm{mg} / \mathrm{L}\end{array}$ & $\begin{array}{l}\text { viscosity } \\
/ \mathrm{mPa} \cdot \mathrm{s}\end{array}$ & & & & \\
\hline \multirow{4}{*}{$\begin{array}{l}25 \\
\text { million }\end{array}$} & 1000 & 45.0 & 299.9 & 44.76 & 40.9 & 6.7 \\
\hline & 2000 & 95.0 & 224.9 & 18.59 & 101.3 & 12.2 \\
\hline & 2500 & 241.0 & 270.0 & 13.64 & 257.5 & 19.8 \\
\hline & 3000 & 391.0 & 244.3 & 11.16 & 352.4 & 21.9 \\
\hline
\end{tabular}

\section{Injectivity evaluation experiment}

According to the measured result of resistance coefficient and residual resistance factor, carry out injectivity evaluation experiment for polymer with different concentrations to measure flow characteristic of different concentration of polymer in natural core $(\mathrm{Q} \sim \Delta \mathrm{P})$, the experiment result of different polymer injectivity is summarized as shown in Figure 2:

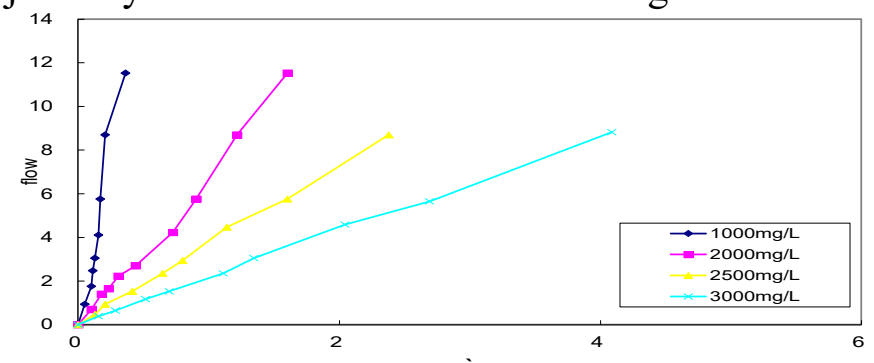

Fig. 2 flow characteristic curves of polymer with different concentrations

From injectivity evaluation experimental result, it can be seen that high concentration polymer can be injected. From the flow characteristic curve of polymer, it can be seen $1000 \mathrm{mg} / \mathrm{L}$ polymer 
has higher injectivity, while the needed injection pressure difference during polymer injection process when concentration exceeds $1000 \mathrm{mg} / \mathrm{L}$ is great. Meanwhile, consideration of residual resistance factor and corresponding concentration of various polymers, injection speed should be within the range $0.25 \sim 0.30 \mathrm{~mL} / \mathrm{min}$.

\section{One-dimensional longitudinal heterogeneous core displacement experiment}

(As is shown in Table 2), it carries out displacement physical simulation experiment, evaluates displacement effect of injecting high concentration polymer after polymer flooding. It applies one-dimensional vertical heterogeneous artificial three-layer core.

Table 2 Three layer core physical parameters of the one-dimensional vertical heterogeneous artificial

\begin{tabular}{c|c|c|c|c|c}
\hline \multirow{2}{*}{ layer } & \multicolumn{3}{|c|}{ layer } & \multirow{2}{*}{$\begin{array}{c}\text { Permeability } \\
\left(10^{-3} \mu \mathrm{m} 2\right)\end{array}$} & porosity(\%) \\
\cline { 2 - 5 } & thickness & width & length & 300 & 24.0 \\
\hline low permeability layer & 1.5 & 4.5 & 30 & 700 & 26.0 \\
\hline medium permeability layer & 1.5 & 4.5 & 30 & 1100 & 30.5 \\
\hline high permeability layer & 1.5 & 4.5 & 30 & 700 & 26.5 \\
\hline full model & 4.5 & 4.5 & 30 & \\
\hline
\end{tabular}

By applying $2.5 \times 107$ molecular weight polymer, carry out displacement experiment at different injection pore volumes according to injection concentration 3000, 2500 and $2000 \mathrm{mg} / \mathrm{L}$. Four experimental schemes are completely in total and the experimental result is shown in Table 3.

Table 3 the change of oil recovery rate in different concentrations of polymer flooding

\begin{tabular}{c|c|c|c|c}
\hline \multirow{2}{*}{ No. } & \multicolumn{4}{|c}{ Recovery ratio(\%) } \\
\cline { 2 - 5 } & $\begin{array}{c}\text { Water flooding } \\
\text { stage }\end{array}$ & $\begin{array}{c}\text { Common polymer } \\
\text { flooding stage }\end{array}$ & $\begin{array}{c}\text { High concentration } \\
\text { polymer flooding } \\
\text { stage }\end{array}$ & Overall process \\
\hline (1) & 36.04 & 24.12 & - & 60.16 \\
\hline (2) & 36.22 & 24.48 & 8.35 & 69.05 \\
\hline (3) & 35.70 & 24.20 & 10.21 & 70.11 \\
\hline (4) & 36.12 & 24.55 & 9.81 & 70.48 \\
\hline (5) & 36.02 & 24.35 & 10.51 & 70.88 \\
\hline (6) & 35.82 & 25.14 & 11.48 & 72.44 \\
\hline
\end{tabular}

Common polymer displacement experimental result indicates that when injection concentration of polymer reaches $1000 \mathrm{mg} / \mathrm{L}$, the recovery percentage of module is about $60 \%$. Afterwards, apply high concentration polymer for displacement so as to improve recovery ratio further at different degrees.

Optimum concentration exists on the same poly-dosage and the corresponding recovery increasing range is largest. For $2.5 \times 107$ molecular polymer, under the same dosage, when the concentration increases from $2000 \mathrm{mg} / \mathrm{L}$ to $2500 \mathrm{mg} / \mathrm{L}$, high concentration polymer flooding recovery increases by $1.86 \%$. When the concentration increases to $3000 \mathrm{mg} / \mathrm{L}$ further, high concentration polymer flooding recovery drops by $0.4 \%$ on the contrary. It reaches about $10 \%$.

(1) On the condition of same concentration, with the increasing of volume injected into pore, recovery ratio increasing range of high concentration polymer flooding is larger. When the concentration is $3000 \mathrm{mg} / \mathrm{L}$, the recovery contrast of dosage $(0.33 \mathrm{PV}, 0.4 \mathrm{PV}$ and $0.5 \mathrm{PV})$ of 
polymer at different segments is shown as scheme 4, 5 and 6 in Table 2.

(2) On the condition of the same injected volume into pore, with the increasing of injection concentration, the recovery ratio increasing range of high concentration polymer flooding is larger. When injecting $0.4 \mathrm{PV}$, concentration rises from $2500 \mathrm{mg} / \mathrm{L}$ to $3000 \mathrm{mg} / \mathrm{L}$ and recovery ratio increases $0.3 \%$; when injecting $0.5 \mathrm{PV}$, concentration rises from $2000 \mathrm{mg} / \mathrm{L}$ to $3000 \mathrm{mg} / \mathrm{L}$ and recovery ratio increases $3.13 \%$.

\section{Large-scale simulation physical model displacement experiment}

According to geologic characteristic of glycosyl I 1 oil layer in North No.2 of East-west Block and oil layer condition and physical parameters of pilot zone, based on the existed well pattern distribution and well pattern reconstruction, design and make large-scale and longitudinal heterogeneous physical simulation model with proportional homogeneity on the plan.

Select 5-point method area well pattern to establish plan model, including 1 injection well and 4 recovery wells. Geometrical size of model is $60 \mathrm{~cm} \times 60 \mathrm{~cm} \times 4.5 \mathrm{~cm}$ and the permeability of each layer is $300 \times 10-3 \mu \mathrm{m} 2,700 \times 10-3 \mu \mathrm{m} 2$ and $1100 \times 10-3 \mu \mathrm{m} 2$ from top to bottom. In planar model, arrange 8 pairs of electrode for each row and line of low and medium permeability layer for collecting data of oil-water front, 128 electrode detection points in total. Utilize oil-water front real-time monitoring technology to study front push difference and sweep coefficient of polymer flooding and when combination segment of high concentration and high polymer plugs flooding after polymer flooding.

\subsection{Experimental scheme}

Model water flooding reaches $92 \%+$ water content of polymer flooding.

After the end of common polymer flooding, carry out high molecular and high concentration displacement experiment, monitor the variation of injection pressure and water content ratio, compute recovery ratio, utilize oil-water front real-time monitoring technology to study front push difference and sweep coefficient of polymer flooding and when combination segment of high concentration and high polymer plugs flooding after polymer flooding.

\subsection{Recovery ratio and injection pressure variation}

Table 4 illustrate recovery ratio of 4 experimental schemes.

Table 4 experimental results of polymer flooding in large scale simulation physics model

\begin{tabular}{c|c|c|c|c}
\hline & $\begin{array}{c}\text { water } \\
\text { flooding } \\
\text { experimental scheme } \\
\text { recovery ratio } \\
(\%)\end{array}$ & $\begin{array}{c}\text { common polymer } \\
\text { flooding recovery } \\
\text { ratio } \\
(\%)\end{array}$ & $\begin{array}{c}\text { high } \\
\text { concentration } \\
\text { polymer } \\
\text { flooding } \\
\text { recovery ratio } \\
(\%)\end{array}$ & $\begin{array}{c}\text { total } \\
\text { recovery } \\
\text { ratio } \%)\end{array}$ \\
\hline $\begin{array}{c}\text { transfer injection after } \\
\text { common polymer } \\
\text { flooding2000mg/L }\end{array}$ & 36.12 & 23.59 & 6.52 & 66.23 \\
\hline $\begin{array}{c}\text { transfer injection after } \\
\text { common polymer flooding } \\
2500 \mathrm{mg} / \mathrm{L}\end{array}$ & 35.13 & 24.17 & 7.05 & 66.35 \\
\hline $\begin{array}{c}\text { well pattern } \\
\text { reconstruction+2000mg/L }\end{array}$ & 35.16 & 23.69 & 7.95 & 66.80 \\
\hline $\begin{array}{c}\text { well pattern reconstruction } \\
+2500 \mathrm{mg} / \mathrm{L}\end{array}$ & 35.55 & 24.49 & 8.54 & 68.58 \\
\hline
\end{tabular}




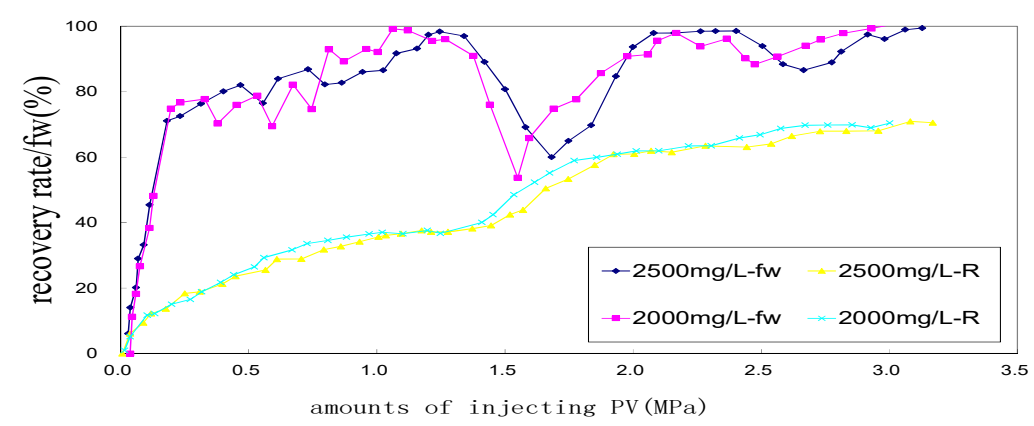

Fig. 3 dynamic curve of polymer flooding in the original well pattern

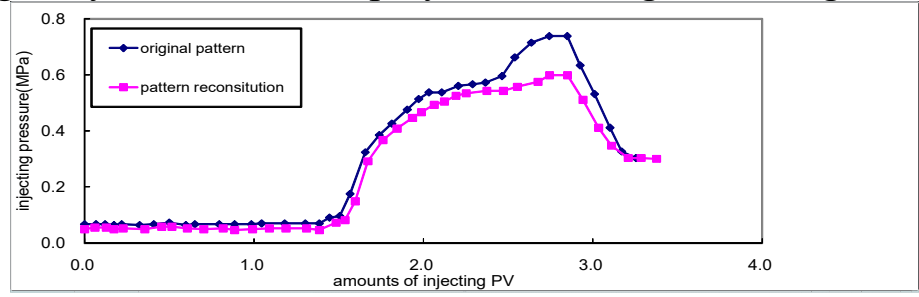

Fig. 4 dynamic curve of polymer flooding in well pattern reconstruction

Physical model displacement experimental result indicates that high concentration polymer flooding recovery is closely related to injection and recovery way. Well pattern reconstruction can reduce remaining oil saturation of common polymer and recovery ratio at high concentration polymer flooding is $1.43 \%$ and $1.49 \%$ higher than double injection and double recovery way in the case of the same concentration. In addition, well pattern reconstruction not only improves recovery ratio, but also relives the continuous rising of injection pressure, as is shown in Figure 5.

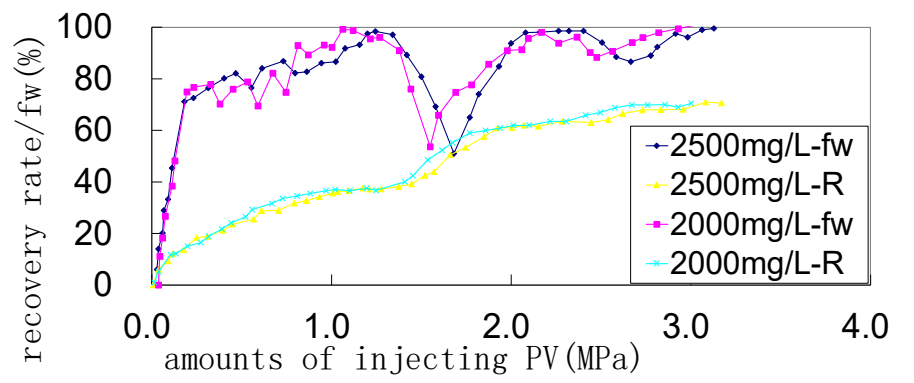

Fig. 5 the change of the injection pressure of $2500 \mathrm{mg} / \mathrm{L}$ into the pressure change curve

\subsection{Sweep efficiency and oil-water front movement}

Sweep coefficient of different schemes and different displacement stages is seen in Table 5.

Table 5 the results of the determination of the sweep coefficient of different solutions and different displacement stages

\begin{tabular}{c|c|c|c|c|c|c}
\hline \multirow{2}{*}{ displacement scheme } & \multicolumn{4}{|c|}{\begin{tabular}{c} 
sweep efficiency \\
\cline { 2 - 7 }
\end{tabular}} & $\begin{array}{c}\text { Water flooding } \\
\text { stage }\end{array}$ & \multicolumn{2}{c|}{$\begin{array}{c}\text { Common polymer } \\
\text { flooding }\end{array}$} & \multicolumn{2}{c}{$\begin{array}{c}\text { high concentration } \\
\text { polymer flooding }\end{array}$} \\
\cline { 2 - 7 } & $\begin{array}{c}\text { permea } \\
\text { bility } \\
\text { layer }\end{array}$ & $\begin{array}{c}\text { medium } \\
\text { permeabi } \\
\text { lity layer }\end{array}$ & $\begin{array}{c}\text { low } \\
\text { permeabili } \\
\text { ty layer }\end{array}$ & $\begin{array}{c}\text { medium } \\
\text { permeabilit } \\
\text { y layer }\end{array}$ & $\begin{array}{c}\text { low } \\
\text { permeabili } \\
\text { ty layer }\end{array}$ & $\begin{array}{c}\text { medium } \\
\text { permeabilit } \\
\text { y layer }\end{array}$ \\
\hline $\begin{array}{c}\text { transfer injection after } \\
\text { common polymer } \\
\text { flooding2000mg/L }\end{array}$ & 0.165 & 0.334 & 0.520 & 0.824 & 0.768 & 0.923 \\
\hline
\end{tabular}




\begin{tabular}{c|c|c|c|c|c|c}
\hline $\begin{array}{c}\text { transfer injection after } \\
\text { common polymer } \\
\text { flooding 2500mg/L }\end{array}$ & 0.184 & 0.350 & 0.516 & 0.840 & 0.790 & 0.965 \\
\hline $\begin{array}{c}\text { well pattern } \\
\text { reconstruction+2000m } \\
\mathrm{g} / \mathrm{L}\end{array}$ & 0.170 & 0.348 & 0.523 & 0.832 & 0.795 & 0.972 \\
\hline $\begin{array}{c}\text { well pattern } \\
\text { reconstruction+2500m } \\
\mathrm{g} / \mathrm{L}\end{array}$ & 0.162 & 0.344 & 0.518 & 0.825 & 0.815 & 0.984 \\
\hline
\end{tabular}

The measured result shows that high concentration polymer flooding after common polymer flooding can make sweep coefficient improved greatly in low and medium permeability layer. Moreover, the higher the concentration is, the bigger the sweep coefficient is.

The variation of oil-water front. Measure oil-water front movement variation of each point and each layer of longitudinal heterogeneous planar model under different injection and recovery ways and different polymer flooding by using oil-water front real-time monitoring system

By analyzing oil-water front distribution of each experiment scheme at different injection stages, it can be observed that:

(1) With the increasing of concentration at high concentration polymer stage, sweep coefficients of low and medium permeability layer are all improved.

(2) On the condition of original well pattern, common polymer flooding and high concentration polymer flooding forms residual oil at the position of diverting stream line and the remaining oil distribution scope of low permeability layer is obviously bigger than that of medium permeability layer.

(3) After well pattern reconstruction, the remaining oil at the position of diverting stream line and nearby oil well in original well pattern is employed, so displacement effect is improved obviously.

\section{Conclusion}

1. In the core with approximate permeability, with the increasing of concentration of polymer, residual resistance factor and resistance coefficient of polymer solution increase.

2. Natural core displacement experiment indicates that (1) Optimum concentration exists on the same poly-dosage and the corresponding recovery increasing range is largest. (2) On the condition of same concentration, with the increasing of volume injected into pore, recovery ratio increasing range of high concentration polymer flooding is larger. (3) On the condition of the same injected volume into pore, with the increasing of injection concentration, the recovery ratio increasing range of high concentration polymer flooding is larger.

3. Large-scale simulation physical model indicates that (1) no matter for which well pattern, injecting high concentration polymer solution can enhance recovery of high polymer flooding obviously, but high concentration polymer flooding recovery is closely related to injection and recovery way. Well pattern reconstruction can reduce remaining oil saturation of common polymer and well pattern reconstruction also relives the continuous rising of injection pressure. (2) With the increasing of concentration at high concentration polymer stage, sweep coefficients of low and medium permeability layer are all improved; On the condition of original well pattern, common polymer flooding and high concentration polymer flooding forms residual oil at the position of diverting stream line and the remaining oil distribution scope of low permeability layer is obviously bigger than that of medium permeability layer; (3) After well pattern reconstruction, the remaining oil at the position of diverting stream line and nearby oil well in original well pattern is employed, so displacement effect is improved obviously. 


\section{References}

[1]. Lu Xiangguo,Gao henhuan. istribution regular pattern research of oil remaining after polymer flooding [J]. IP, 1996, 17(4):55-56.

[2]. Song kaoping, Yang Feng,Shu Zhihua,,et al The affecting factor ofmicrocosmic distribution of polymer flooding oil remaining[J]. Daqing Petroleum Institute Journal，2004， 28(2): 25-27.

[3]. Peng hongli,Zhou xiaoping,Yao Guangju,et al. Distribution regular pattern of microcosmic full oil remaining after high capacity channel reservoir polymer flooding

[4]. Hou jian,Zhang Shunkang,Yuan Shibao.The quantitative analysis research of the distribution regular pattern of polymer flooding microcosmic infiltrating fluid experiment oil remaining[J].The research and development of hydrodynamics, 2006, 21(1): 42-44. 